\section{Discussion}

Primary arteritis of the aorta is a distinct entity. Earlier descriptions of Takayasu's disease, ${ }^{1}$ brachial arteritis, ${ }^{2}$ and aortic arch syndrome ${ }^{3}$ cover only one facet, and may be misleading. More recent reports ${ }^{45}$ based on necropsy or angiographic findings suggest that occlusive changes may affect any part of the aorta and its branches.

This present case presented with renovascular hypertension. Patchy narrowing of the abdominal aorta with its accompanying calcification and partial occlusion of the left renal artery with non-specific histological findings strongly suggest the diagnosis of primary aortitis. Removal of the stenosed vessel and affected kidney restored the blood pressure to near normal levels.

The aetiology of this apparently rare condition remains obscure. The disease may well represent the end result of a variety of different initiating agents, the anatomical site of disease being modified by other unknown variables.

1 Takayasu, M, Acta Societatis Ophthalmologicae faponicae, 1908, 12, 554.

2 Koszewski, B J, Angiology, 1958, 9, 180.

3 Judge, R D, et al, American fournal of Medicine, 1962, 32, 379.

4 Schrire, V, and Asherson, R A, Quarterly fournal of Medicine, 1964, 33, 439.

${ }^{5}$ Munoz, N, and Correa, P, American Heart fournal, 1970, 80, 319.

Ndola Central Hospital, Ndola, Zambia

WALL, R.A, MB, MRCP, senior registrar, department of medicine.

SIKAND, P C, MD, FRCP, consultant physician

ELEM, B, MB, FRCS, consultant urologist

\section{Discussion}

This patient inadvertently took Ovral for the first three months of her pregnancy and gave birth to an infant with a tracheo-oesophageal fistula, an abnormality whose normal occurrence is 1 in 3000. This association was also reported by Oakley $e t a l^{2}$ in a letter to the Lancet on the relation between hormonal pregnancy tests and congenital malformation.

Until it is proved that there is no relation between these preparations and congenital abnormality it is prudent to ensure that no patient is prescribed oral contraceptives unless pregnancy has been definitely excluded. ${ }^{3}$

${ }^{1}$ Nora, J L, and Nora, A H, New England fournal of Medicine, 1974, 291, 732 .

2 Oakley, G P, Flynt, W J, and Falck, A, Lancet, 1973, 2, 256.

${ }^{3}$ British Medical fournal, 1974, 4, 485.

Department of Obstetrics and Gynaecology, University of Rhodesia, PO Box ST 494, Salisbury, Rhodesia

OLIVE FROST, MB, MRCOG, senior lecturer

\title{
Neurological manifestations in a patient with filariasis
}

Filariasis, in particular infections with Loa loa and Depetalonema perstans, may occasionally develop some neurological complications. ${ }^{12}$ However, these are neither common nor well known. We believe it important to call attention to them because they can be mistaken for a neurological disease of different aetiology. For that reason we report following case.

\section{Case report}

Progestogen/oestrogen preparations have been suspected as potentially teratogenic drugs for several years but reports are conflicting. It is therefore important to document all cases where congenital abnormality is associated with the ingestion of the drugs during pregnancy. ${ }^{1}$ I report here such a case.

\section{Case report}

A 23-year-old primigravida was booked for hospital delivery at about the 20th week of pregnancy. Her last menstrual period had been on 22 March 1975 , thus making her expected date of delivery 29 December 1975 . Nevertheless, she had taken the oral contraceptive Ovral (Di-norgenstril $0.5 \mathrm{mg}$, and ethinyl oestradiol $0.05 \mathrm{mg}$ ) regularly until June 1975 . At this time a vaginal examination performed to elicit the cause of 12 weeks' amenorrhoea confirmed a 12 weeks' size pregnancy. The patient attended antenatal clinic regularly for a total of 14 visits. The size of the uterus was initially small for dates and later large for dates owing to hydramnios. The result of a glucose tolerance test was normal and an $x$-ray film showed a normal singleton fetus. The hydramnios, therefore, was of unknown origin. On 20 January 1976, when the pregnancy was post term by dates, there was a slight rise in blood pressure and induction of labour was considered. Clinically the fetus was of good size and the amniotic fluid gave a positive "bubble" test and contained $20 \%$ fat staining cells with Nile blue sulphate reagent. Induction of labour was planned, and was performed on 23 January 1976. Hind-water and forewater rupture of membranes resulted in the drainage of over $4000 \mathrm{ml}$ of clear liquor. A syntocinon infusion at $1 \mathrm{~m} \mu$ unit/minute was begun and the dose doubled every 30 minutes to $4 \mathrm{~m} \mu / \mathrm{min}$, when labour was established. The latent phase of the first stage of labour lasted four hours and the active phase six hours. A delayed second stage was terminated by an easy vacuum extraction and the third stage of three minutes was uneventful. The puerperium was normal apart from a slight rise of blood-pressure for the first 24 hours after delivery.

The baby girl weighed $3000 \mathrm{~g}$ and the Apgar score at one and five minutes was 8. A nasogastric tube could not be passed and an oesophageal atresia with a fistula between the distal segment and the trachea was confirmed on $x$-ray examination. A repair was performed on the same day. Her postoperative progress was stormy. A gastrostomy was performed on 29 January 1976 and closure of fistulous track on 19 February 1976. After the latter her general condition improved, but she died from bronchopneumonia on $28 \mathrm{March}$ 1976.

A 28-year-old Negro male born in Rio Muni, West Africa, was admitted to hospital because 10 days previously he had started to complain of vomiting, unsteadiness, loss of hearing on the left side, and paraesthesiae on the left side of the face. Clinical examination disclosed hepatosplenomegaly, nystagmus, sensorineural hypoacusis, and signs of,left facial paresis. Blood analysis showed eosinophilia of $18 \%$ and numerous microfilariae, later identified as Loa loa and $D$ perstans. No plasmodia were seen. Blood chemistry, urine analysis, stool examination, and serological tests for Echinococcus granulosus and toxoplasma were all normal. In a bone marrow aspiration a high eosinophil count was the only abnormality. An electrocardiogram showed $\mathrm{T}$ wave inversions on V1 to V5. Lumbar puncture yielded clear fluid with $45 \mathrm{mg} / 100$ $\mathrm{ml}(0.45 \mathrm{~g} / \mathrm{l})$ protein, $76 \mathrm{mg} / 100 \mathrm{ml}(4.2 \mathrm{mmol} / \mathrm{l})$ glucose, and $45 \mathrm{cells}$. The presumptive diagnosis of cerebellopontine angle tumour or acoustic neuroma was made. Cerebral angiographic, pneumoencephalographic, and echoencephalographic studies were all normal.

One month after symptoms began spontaneous recovery set in, and all the symptoms completely disappeared without treatment in two more weeks.

\section{Discussion}

The clinical picture in this case suggested a lesion in the cerebellopontine angle which subsided spontaneously, leaving no sequel about two months later. A careful clinical examination showed no specific cause for it. The only abnormal finding was a severe infection of the blood with Loa loa and D perstans microfilariae. Both species and Meningonema peruzzi have been implicated in the production of cerebral symptoms. Some authors ${ }^{134}$ have reported cases of fatal meningoencephalitis or cases with focal symptoms that subsided spontaneously. ${ }^{5}$

We were unable to find microfilariae in the CFS as has been reported in other cases. We cannot be certain that the patient's symptoms were due to filariasis, and we cannot rule out a viral infection or even a minor cerebrovascular accident. Nevertheless, it is possible that filariasis was responsible for neurological symptoms, and we emphasise the need to consider this possibility in the diagnosis of any neurological syndrome in a patient coming from countries where these helminthiasis are endemic. 